\title{
Hemopressin increases penicillin-induced epileptiform activity in rats
}

\author{
Aygun $\mathrm{H}^{1}$, Arslan $\mathrm{G}^{2}$, Sen $\mathrm{E}^{2}$, Ayyildiz $\mathrm{M}^{2}$, Agar $\mathrm{E}^{2}$ \\ Department of Physiology, Faculty of Medicine, Tokat Gaziosmanpasa University, Tokat, Turkey. \\ hatice_5aygun@hotmail.com
}

\section{ABSTRACT}

OBJECTIVE: Hemopressin $(\mathrm{Hp})$ is the first peptide ligand described for the CB1 cannabinoid receptor. Therefore, we aimed to investigate the effect of hemopressin on pencillin-induced epileptiform activity by using electrophysiological recording (ECoG) technique.

METHODS: Male Wistar rats were anesthetized with urethane $(1.25 \mathrm{~g} / \mathrm{kg})$, and epileptiform activity was induced by intracortical injection of penicillin (500 IU). Animals were randomly divided into eight groups. Subsequently, the rats were administered with saline or hemopressin as follows: saline control group (Group I: $2 \mu$ l/i.c.v/saline), hemopressin groups (Group II: $0.025 \mu \mathrm{g} / \mathrm{i} . c . v ;$ Group III: $0.075 \mu \mathrm{g} / \mathrm{i.c.v}$; Group IV: $0.15 \mu \mathrm{g} /$ i.c.v; Group V: $0.3 \mu \mathrm{g} / \mathrm{i} . c . v ;$ Group VI: $0.6 \mu \mathrm{g} / \mathrm{i} . c . v$; Group VII: $1.2 \mu \mathrm{g} / \mathrm{i.c.v}$; Group VIII: $2.4 \mu \mathrm{g} / \mathrm{i.c.v}$ ). The various

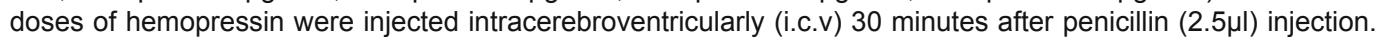
After hemopressin injection, ECoGs were recorded for three hours.

RESULTS: $\mathrm{Hp}$ at doses of $0.075,0.15,0.3,0.6,1.2$ and $2.4 \mu \mathrm{g} / \mathrm{kg}$ significantly increased the frequency of epileptiform ECoG activity compared to penicillin-injected group without changing the amplitude. The $0.6 \mu \mathrm{g}$ hemopressin was the most effective dose to increase the epileptiform activity $(p<0.05)$ while the dose of $0.025 \mu \mathrm{g}$ hemopressin was non-effective $(p>0.05)$.

CONCLUSIONS: The results of this study provided electrophysiological evidence for hemopressin to be modulating penicillin-induced epileptiform activity by acting as $\mathrm{CB}_{1}$ receptor antagonist. Further studies are required to elucidate the involved mechanism underlying this effect (Fig. 3, Ref. 40). Text in PDF www.elis.sk. KEY WORDS: cannabinoid, $\mathrm{CB}_{1}$, epilepsy, hemopressin, penicillin, receptor.

\section{Introduction}

Epilepsy is one of serious chronic neurologic disorders characterized by a lasting predisposition to have epileptic seizures potentially leading to neurological, cognitive, physiological and social problems (1). Studies conducted so far have shown that systems, receptors and peptides involved in epilepsy could be used to protect brain cells during and after seizures or to minimize the resulting damage $(2,3,4)$. Recent studies revealed that the cannabinoid system has considerable roles in controlling and preventing epileptic seizures $(5,6,7)$.

Cannabinoids exert their behavioral and neuronal effects through $\mathrm{CB} 1$ receptor $(8,9,10,11)$. It has been shown that endocannabinoids such as arachidonoyl ethanolamide (anandamide) and 2-arachidonoyl glycerol (2-AG) have a neuroprotective effect on the hippocampus via activating the CB1 receptor $(12,13)$. Endocannabinoids are synthesized from membrane lipids when needed

'Department of Physiology, Faculty of Medicine, Tokat Gaziosmanpasa University, Tokat, Turkey, and ${ }^{2}$ Department of Physiology, Faculty of Medicine, Ondokuz Mayis University, Samsun, Turkey

Address for correspondence: H. Aygun, Dr, Department of Physiology, Faculty of Medicine, Tokat Gaziosmanpasa University, 60030 Tokat, Turkey.

Phone: +90.5399631308 as a response to a prolonged neuronal depolarization and elevated intracellular calcium levels. It is known that a retrograde inhibition of neurotransmitter release and control of neuronal stimulation are conditioned via this mechanism $(9,10,11,14)$. It has been reported that these events take place during seizure (15). Endocannabinoids prevent seizures through a CB1 receptor-dependent mechanism $(16,17)$. CB1 receptor antagonists have been shown to lower the seizure threshold, thereby facilitating epileptogenesis (17). Our group previously showed that the cannabinoid CB1 receptor agonist, arachidonyl-2'-chloroethylamide hydrate (ACEA), is a anticonvulsant, and 1-(2,4-dichlorophenyl)-5-(4-iodophenyl)4-methyl-N-1-piperidinyl-1Hpyrazole-3carboxamide (AM-251) has a proconvulsant effect $(18,19)$. In addition, down-regulation of CB1 receptor and associated molecules have been shown in hippocampus regions which were removed surgically due to temporal lobe epilepsy (20). Thus, CB1 receptors seem to play a significant role in pathophysiology of convulsive seizures.

Hemopressin is the first peptide ligand identified for CB1 cannabinoid receptor (21). Hemopressin (PVNFKFLSH) was previously isolated from rat brain homogenates and was shown to cause hypotension in anesthetized rats (22). Later, Heiman et al (21) discovered hemopressin, a peptide ligand selectively binding CB1 cannabinoid receptors, using conformation state-sensitive antibodies to screen the endogenous peptide panel of rat brain and 
adipose tissue. By using nuclear magnetic resonance spectroscopy and circular dichroism method, Scrima et al (23) verified that hemopressin is indeed the CB1 receptor ligand. Dodd et al (24) studied the effect of hemopressin on dietary behaviors and found no pharmacological effects of it in rats lacking CB1 receptors. Hemopressin is selectively bound to cannabinoid receptors and does not have any effect on receptor family related to other G-proteins, including CB2 receptor $(21,24)$.

Although it has been well established that hemopressin is a CB1 receptor ligand, the question whether it is an agonist or antagonist of cannabinoid CB1 receptor is still disputed. Heimann et al (21) showed that hemopressin decreased the increase in antibody recognition induced by $\mathrm{CB} 1$ agonist, which was the same as the decrease by CB1 receptor antagonist SR141716 (rimonabant). A study in which neuroprotective effects of cannabinoid agonists and antagonists were investigated in rat cerebral ischemia/reperfusion models found that hemopressin slightly suppressed the neuroprotective effect exerted by cannabinoid receptor agonist ACEA (25). Some in vivo/in vitro hemopressin studies showed that cannabinoid receptors acted as an antagonist and passed the blood-brain barrier, while suppressing the appetite and leading to antinociception $(24,26,27)$. Some other studies revealed that hemopressin acted as CB1 receptor agonist. Li et al (28) showed that the effect of hemopressin on gastrointestinal motility was the same as the effect of cannabinoid receptors. Similarly, Pan et al (29) found that hemopressin had an antinociceptive effect in a rate-dependent manner, similar to that of CB1 receptor agonists.

Hemopressin has recently been shown to be closely associated with cannabinoid CB1 receptor system. Cannabinoid CB1 receptor system has been clearly indicated to play a role in epilepsy, but the effect of hemopressin on epilepsy has not been investigated so far. Elucidation of the effect of hemopressin on epileptic activity could probably increase the significance of cannabinoid system in epilepsy. In addition, this will allow a detailed understanding of hemopressin CB1 receptor agonism and antagonism. Thus, the aim of the present study was to investigate the effect of hemopressin on penicillin-induced epileptiform activity in rat. Penicillin epilepsy model is known as a simple partial epilepsy model in the clinic.

\section{Methods}

\section{Animals}

Fifty-six adult male Wistar Albino rats $(210 \pm 10 \mathrm{~g})$ were used for the experiments. Experimental designs and procedures were approved by Ondokuz Mayıs University Animal Research Committee in accordance with the European Commission regulations (2014-HAYDEK-16). Rats were obtained from Ondokuz May1s University Medical and Surgical Research Center (Samsun, Turkey). The rats were housed in cages with 3-4 rats per cage and were kept under standardized conditions (at $20 \pm 3{ }^{\circ} \mathrm{C}$ temperature; 12-hour light - 12- hour dark cycle, lights on at 06:00 a.m.; $55-60 \%$ relative humidity). Standard food pellets and water were available ad libitum

\section{Experimental groups}

After seven days of adaptation to laboratory conditions, the animals were randomly divided into eight groups of seven rats per group. Each rat was used only once. All experimental procedures were performed between 10.00 a.m. and 3.00 p.m. Experimental groups were as follows:

Experiment 1: dose-response relationship of hemopressin (Hp)

(1) 500 units penicillin $(2.5 \mu$ l, i.c. $)$

(2) $500 \mathrm{IU}$ penicillin $(2.5 \mu$ l, i.c. $)+\mathrm{Hp}(0.025 \mu$ g, i.c.v. $)$

(3) $500 \mathrm{IU}$ penicillin $(2.5 \mu$ l, i.c. $)+\mathrm{Hp}(0.075 \mu$ g, i.c.v. $)$

(4) $500 \mathrm{IU}$ penicillin $(2.5 \mu$, i.c. $)+\mathrm{Hp}(0.15 \mu$ g, i.c.v. $)$

(5) $500 \mathrm{IU}$ penicillin $(2.5 \mu$ l, i.c. $)+\mathrm{Hp}(0.3 \mu$ g, i.c.v. $)$

(6) $500 \mathrm{IU}$ penicillin $(2.5 \mu$ l, i.c. $)+\mathrm{Hp}(0.6 \mu \mathrm{g}$, i.c.v $)$

(7) 500 IU penicillin $(2.5 \mu$ l, i.c. $)+\mathrm{Hp}(1.2 \mu$ g, i.c.v $)$

(8) $500 \mathrm{IU}$ penicillin $(2.5 \mu$ l, i.c. $)+\mathrm{Hp}(2.4 \mu$ g, i.c.v $)$

\section{Surgical procedure}

The rats were starved for one day before the operation. Prior to surgery, animals were given anesthesia with an intraperitoneal injection of urethane $(1.25 \mathrm{~g} / \mathrm{kg}$, i.p). Then the rats were placed in a stereotaxic apparatus. The periosteum of the skull was removed by scraping, and small bleeding foci were cauterized by electrocautery to prevent bleeding. In all experiments, bregma was used as a reference point, and implantation co-ordinates were taken from the atlas according to Paxinos and Watson (30). Then, four holes of $0.2 \mathrm{~mm}$ diameter were opened with the help of a microdrill. Tripolar electrodes were placed over the left somatomotor cortex (electrode coordinates: first electrode placed $3 \mathrm{~mm}$ lateral to sagittal suture and $4 \mathrm{~mm}$ rostral to bregma; second electrode was placed $3 \mathrm{~mm}$ lateral to sagittal suture and $4 \mathrm{~mm}$ caudal to bregma). The common reference electrode was fixed on the pinna. During this procedure, bleeding which may occur in the bone tissue was inhibited by bone wax (W810, ETHICON). The body heat of the rats was kept constant with electric blankets (Harvard 7087). Rectal temperature was maintained between 36.0 and $37.5^{\circ} \mathrm{C}$ using a feedback-controlled heating system.

\section{Induction of epileptiform activity}

Penicillin $G$ potassium salt selectively antagonizes the GA$\mathrm{BA}_{\mathrm{A}}$-receptor and mediates inhibitory postsynaptic potentials in the central nervous system. The induction of epileptiform activity was carried out as described previously by Ayy1ldiz et al (31); Esen and Aygun (3). Intracortical (i.c.) injection of penicillin was applied to the cerebral cortex $(2 \mathrm{~mm}$ lateral and $2 \mathrm{~mm}$ rostral to bregma) through a Hamilton microinjector at a depth of $3.2 \mathrm{~mm}$ from the skull bone system. The epileptic focus was produced by 500 units of penicillin $\mathrm{G}$ potassium injection.

\section{Drugs administration}

Hemopressin, urethane and Penicillin G potassium salt were purchased from Sigma Chemical Co., St. Louis, USA. All drugs dissolved in in physiological saline.

Hemopressin (PVNFKFLSH;Sigma Chemical Co., St. Louis, MO, U.S.A.) were used in the experiments. Hemopressin and Penicillin $\mathrm{G}$ potassium salt was dissolved in physiological saline 
and administered intracortically in a volume of 2.5 $\mu 1$. Intracerebroventricular injections were administered into the left lateral ventricle of each rat through a stereotaxic apparatus with coordinates of $1.5 \mathrm{~mm}$ lateral and $1.1 \mathrm{~mm}$ rostral to bregma. Intracerebroventricular (i.c.v) injection of the drug was applied to this hole through a Hamilton microinjector at a depth of $4.2 \mathrm{~mm}$ from the skull bone system (33). In the first set of experiments, hemopressin, was administered $30 \mathrm{~min}$ after penicillin (i.c.) application at doses of $0.025,0.075,0.15,0.3,0.6,1.2$ and $2.4 \mu$ g (i.c.v.).

\section{ECoG recordings}

The electrocorticography (ECoG) activity was continuously monitored on a 16-channel recorder (PowerLab, 16/35, AD Instruments, Castle Hill, Australia). All recordings were made under anesthesia and stored on a computer. The frequency and amplitude of epileptiform ECoG activity was analyzed off-line.

\section{Statistical analyses}

The results for each group are expressed as means \pm standard error of the mean (SEM). Statistical comparisons were made using SigmaStat software (SPSS Science, Chicago, IL, U.S.A.). The data analysis was performed using one-way analysis of variance (ANOVA) and Tukey tests for comparisons. Differences were considered statistically significant at $\mathrm{p}<0.05$.

\section{Results}

Intracortical injection of penicillin (500 IU) induced an epileptiform ECoG activity characterized by bilateral spikes and spike-wave complexes (Fig. 1A). This ECoG activity began within 3-5 min after penicillin injection and lasted for $5 \mathrm{~h}$. It reached a constant level of frequency and amplitude in $30 \mathrm{~min}$. The mean spike frequency and amplitude were 37.54 $\pm 3.21 \mathrm{spike} / \mathrm{min}$ and $932.97 \pm 30.24 \mu \mathrm{V}$ within 90 min after physiological saline injection (i.c.v.), respectively. Hemopressin (Hp) was administered 30 min after penicillin injection.

Hemopressin, at a dose of $0.025 \mu \mathrm{g}$, did not affect the mean frequency and amplitude of penicillininduced epileptiform activity (Figs 1B, 2 and 3). Hemopressin at doses of $0.075,0.15,0.3,0.6,1.2$ and $2.4 \mu \mathrm{g}$ significantly enhanced the mean frequency of epileptiform activity without changing the amplitude (Figs 2 and 3). However, the dose of $0.6 \mu \mathrm{g}$ was the most effective in increasing the mean frequency.

The mean frequency of epileptiform ECoG activity in groups administered with hemopressin at
A) Penicillin G (500 IU)

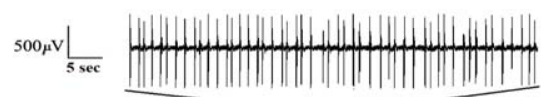

H.

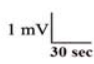

B) Penicillin G (500 IU) + Hp (0.025 $\mu \mathrm{g})$

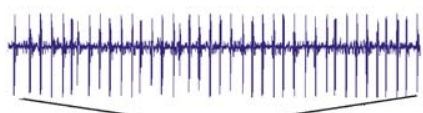

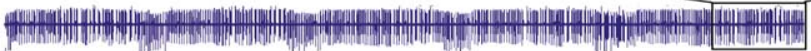

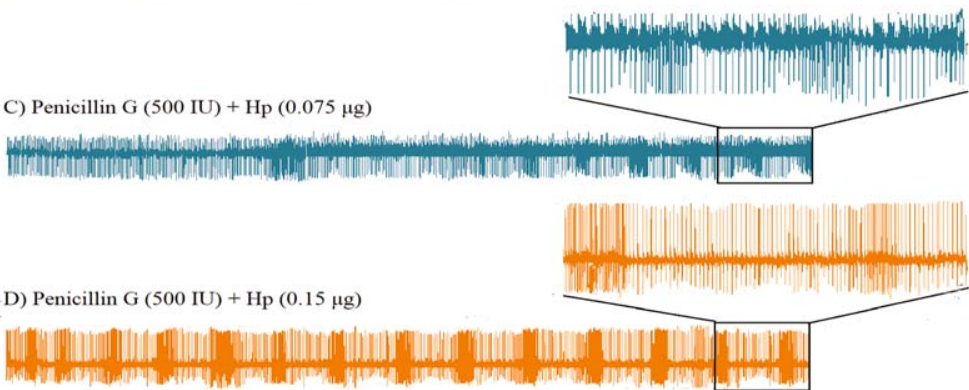

D) Penicillin G (500 IU) + Hp (0.15

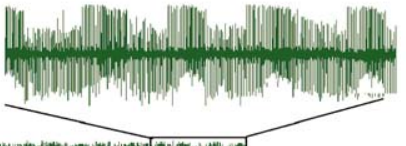

E) Penicillin G (500 IU) + Hp $(0.3 \mu \mathrm{g})$
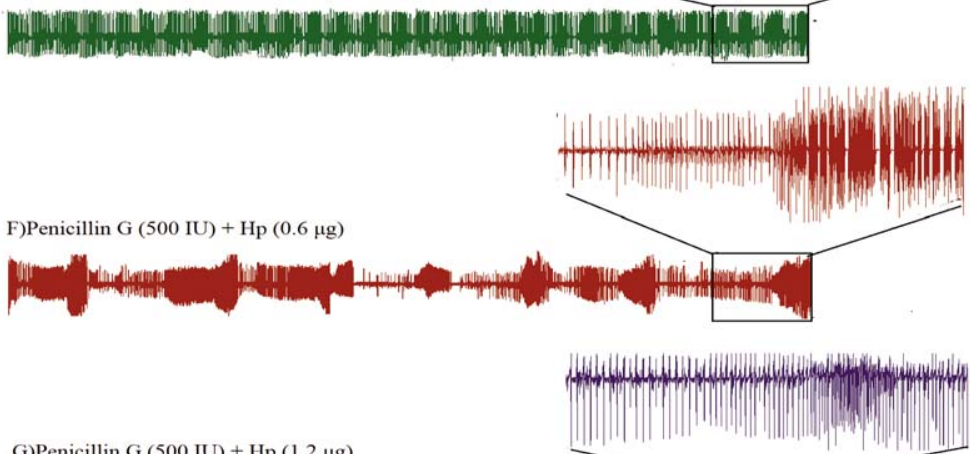

G)Penicillin G (500 IU) + Hp (1.2 $\mu \mathrm{g})$

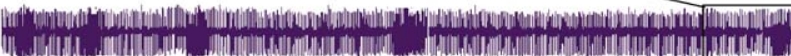

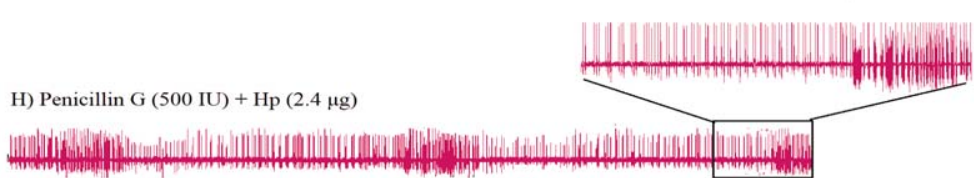

Fig. 1. The intracortical injection of penicillin (500 IU) induced the epileptiform activity on ECoG (A). The intracerebroventricular (i.c.v.) administration of $\mathrm{Hp}$ at the low doses of $0.025 \mu \mathrm{g} / \mathrm{kg}$, i.p., $30 \mathrm{~min}$ after penicillin injection did not significantly change the frequency and amplitude of epileptiform ECoG activity (B). The administration of $0.075 \mu \mathrm{g}$ Hp caused a marked increase in the frequency of penicillin-induced epileptiform activity within $\mathbf{1 1 0}$ min after $\mathrm{Hp}$ injection without changing the amplitude (C). The administration of $0.15 \mu \mathrm{g}$ Hp caused a marked increase in the frequency of penicillin-induced epileptiform activity within 50 min after Hp injection without changing the amplitude (D). The administration of $0.3 \mu \mathrm{g}$ Hp caused a marked increase in the frequency of penicillin-induced epileptiform activity within $\mathbf{5 0}$ min after Hp injection without changing the amplitude (E). The administration of 1.2 $\mu \mathrm{g}$ Hp caused a marked increase in the frequency of penicillin-induced epileptiform activity within 100 min after $\mathrm{Hp}$ injection without changing the amplitude (F). The administration of $2.4 \mu \mathrm{g} \mathrm{Hp}$ caused a marked increase in the frequency of penicillininduced epileptiform activity within $130 \mathrm{~min}$ after $\mathrm{Hp}$ injection without changing the amplitude (G). Hp (0.075,0.15, 0.3, 0.6, 1.2 and $2.4 \mu \mathrm{g})$ also caused the development of status epilepticus-like activity. 


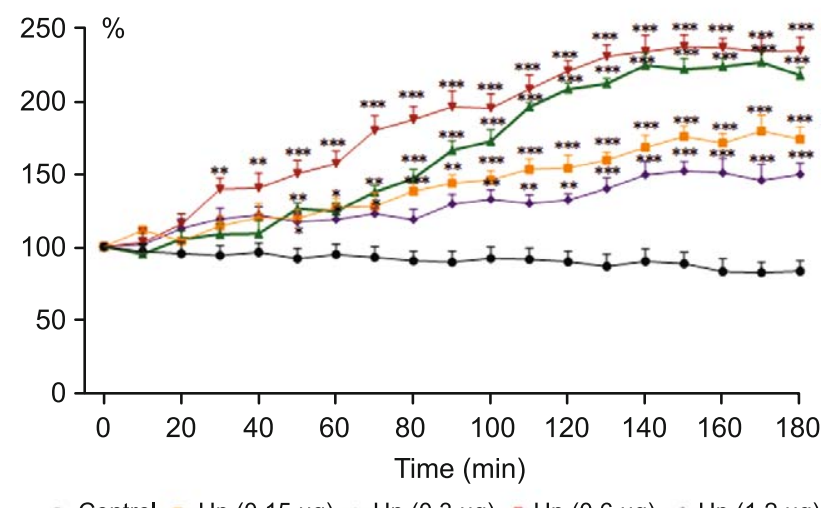

$\bullet-$ Control $=-\mathrm{Hp}(0.15 \mu \mathrm{g}) \rightarrow \mathrm{Hp}(0.3 \mu \mathrm{g}) \rightarrow-\mathrm{Hp}(0.6 \mu \mathrm{g}) \rightarrow-\mathrm{Hp}(1.2 \mu \mathrm{g})$

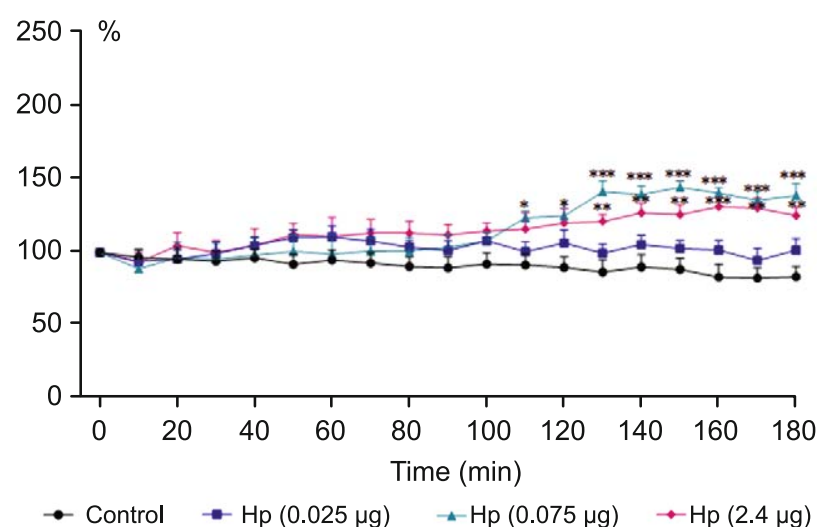

Fig. 2. The effects of intracerebroventricular administration of $\mathrm{Hp}$ on mean spike frequency of penicillin-induced epileptiform activity. Hp at a rate of $0.025 \mu \mathrm{g} / \mathrm{kg}$ did not influence mean frequency or amplitude of epileptiform activity. Hp rates of $0.075,0.15,0.3,0.6,1.2$ and $2.4 \mu \mathrm{g} /$ $\mathrm{kg}$ i.c.v. increased the mean spike frequency of epileptiform activity within 110, 50, 50, 30, 100 and 130 min after $\mathrm{Hp}$ injection, respectively, compared to penicillin-injected groups (control groups); *p < $0.05, * * p<0.01, * * * p<0.001$. The percent frequency of epileptiform ECoG activity value (defined as mean of spike frequency after substance is administered / mean of spike frequency before substance is administered * 100) depends on both frequencies of epileptiform ECoG activity before and after the substance is administered.

doses of $0.025,0.075,0.15,0.3,0.6,1.2$ and $2.4 \mu \mathrm{g}$ were $42.00 \pm$ $3.07,55.26 \pm 2.66 ; 51.30 \pm 1.65,51.61 \pm 1.72,58.65 \pm 3.86,52.85$ \pm 3.45 , and $50.88 \pm 2.08 \mathrm{spike} / \mathrm{min}$, respectively, within $90 \mathrm{~min}$ after Hp $(0.025 \mu \mathrm{g}) ; 110 \mathrm{~min}$ after $\mathrm{Hp}(0.075 \mu \mathrm{g}) ; 50 \mathrm{~min}$ after $\mathrm{Hp}(0.15 \mu \mathrm{g}) ; 50 \mathrm{~min}$ after $\mathrm{Hp}(0.3 \mu \mathrm{g}) ; 30 \mathrm{~min}$ after $\mathrm{Hp}(0.6 \mu \mathrm{g})$; $100 \mathrm{~min}$ after $\mathrm{Hp}(1.2 \mu \mathrm{g})$ and $130 \mathrm{~min}$ after $\mathrm{Hp}(2.4 \mu \mathrm{g})$ injection, respectively. The amplitude of ECoG activity in the latter groups was $820.90 \pm 45.77,998.94 \pm 37.99,880.50 \pm 32.16,1096.96 \pm$ $35.39,1063.94 \pm 65.73,943.45 \pm 36.28$, and $979.55 \pm 38.69 \mu \mathrm{V}$ respectively (Figs 2 and 3 ).

\section{Discussion}

In the present study, the effect of hemopressin was investigated in penicillin-induced experimental epilepsy model. Hemopressin caused an increment in the mean frequency of epi-
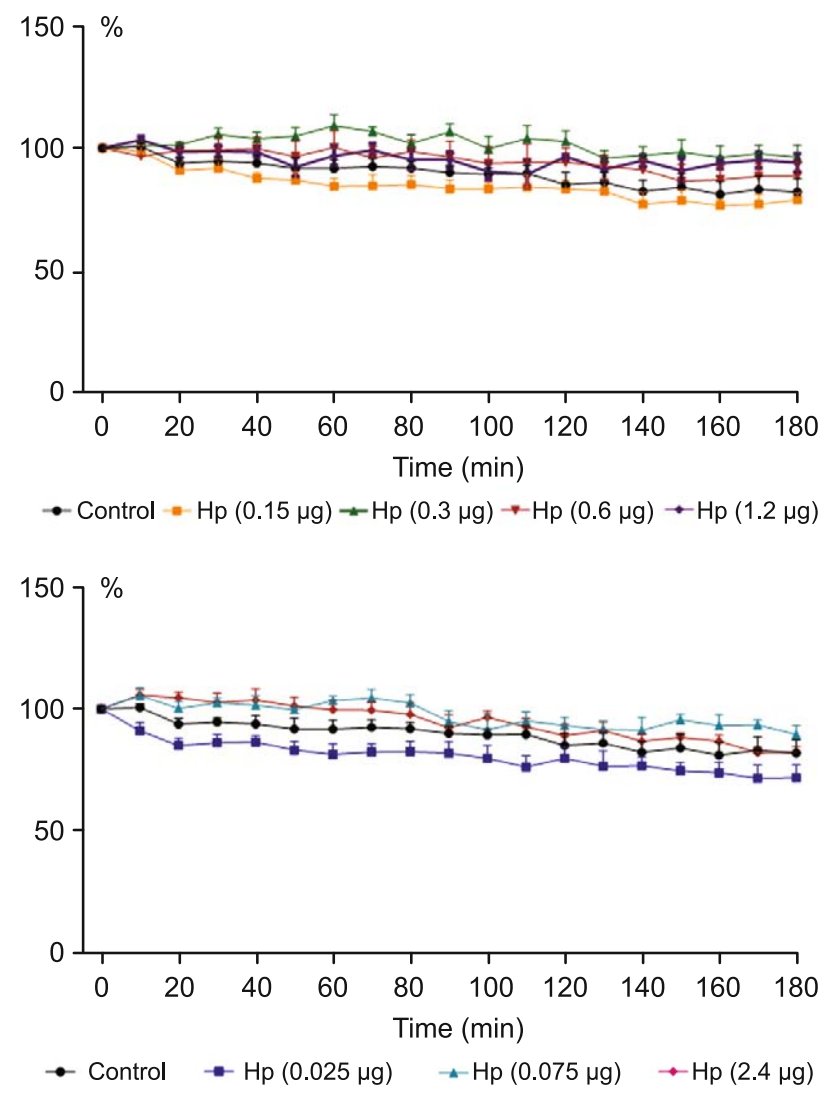

Fig. 3. The effects of $\mathrm{Hp}$ on mean spike amplitude of penicillin-induced epileptiform activity. Hp at rates of $0.025,0.075,0.15,0.3,0.6,1.2$ and $2.4 \mu \mathrm{g} / \mathrm{kg}$, i.c.v, did not change amplitude of epileptiform activity. The percent amplitude of epileptiform ECoG activity value (defined as mean of spike amplitude after substance is administered / mean of spike amplitude before substance is administered*100) depends on both frequencies of epileptiform ECoG activity before and after the substance administration.

leptiform activity in various doses of hemopressin injection. The dose of hemopressin $0.6 \mu \mathrm{g}$ was most effective in increasing the epileptiform activity. The small dose of hemopressin $(0.025 \mu \mathrm{g})$ was not effective.

Heimann et al (21) used $50 \mu \mathrm{g} / \mathrm{kg}$ (i.p.) and $500 \mu \mathrm{g} / \mathrm{kg}$ (i.p.) rates of hemopressin and observed antinociceptive effect by both rates. They found that the antinociceptive effect was highest at $500 \mu \mathrm{g} / \mathrm{kg}$ rate. In another study, $500 \mathrm{nmol} / \mathrm{kg}$ (i.p.) application of hemopressin decreased food intake in rats (24). Fogaça et al (34) showed that $0.05 \mathrm{mg} / \mathrm{kg}$ (i.p) and $0.5 \mathrm{mg} / \mathrm{kg}$ (oral) administration of hemopressin resulted in anxiogenic-like effects in Wistar rats. In a study dealing with neuroprotective effects of cannabinoid agonist and antagonists using cerebral ischemia/reperfusion rat model, administration of $1 \mathrm{mg} / \mathrm{kg}$ i.p. of hemopressin partly suppressed the neuroprotective effect induced by cannabinoid receptor agonist ACEA (25). In general, ICV applications are one in one thousand of IP applications. In the present study, the most effective dose of hemopressin was $0.6 \mu \mathrm{g}$ (ICV) while that of 0.025 $\mu \mathrm{g}$ was non-effective. 
Heiman et al (21) screened endogenous peptide panel of rat brain tissue using conformation state-sensitive antibodies and found that only hemopressin could modulate antibody binding considerably and thus could be a potential ligand for CB1 receptors. More recently, Scrima et al (23) studied structural features of hemopressin using circular dichroism and nuclear magnetic resonance spectroscopy. Based on findings about the coefficients of energy value, binding and clamping, hemopressin was shown to interact with $\mathrm{CB} 1$ receptor. On the other hand, another study using CB1 knock-out rats failed to show the effects of hemopressin on food uptake (24). All studies with hemopressin showed that it selectively binds to $\mathrm{CB} 1$ receptor. However, the question of whether it is an agonist or antagonist is still controversial. While in some cases, hemopressin appears to be a CB1 receptor antagonist because of its effect on appetite and some main pathways, in other cases, it acts as a CB1 receptor agonist for gastrointestinal system.

There are many studies in literature reporting that $\mathrm{CB} 1$ receptors affect epileptiform activity $(6,7,11,18,35)$. Most studies showed that cannabinoid CB1 receptor agonists have anticonvulsant effect. Wallace et al. found that an elimination of endogenous cannabinoid tonus increased the seizure susceptibility (17). In other studies, the release of glutamate through CB1 receptor in gluamatergic axon terminals was reduced as a result of anticonvulsant effect $(36,37)$. In pilocarpine epilepsy model established in rats, $\Delta 9$ - THC (10 mg/kg) completely eliminated epileptic discharges of CB1 receptor agonist WIN55,212 (5 mg/kg), while CB1 receptor antagonist SR141716A significantly increased both length and frequency of seizures (38). If hemopressin had acted as a CB1 receptor agonist, it would have exerted an anticonvulsant effect. However, hemopressin had a proconvulsant effect in that study. Therefore, it could be stated that hemopressin functions as a CB1 receptor antagonist.

In the present study, hemopressin showed a proconvulsant effect albeit sometimes late in all rates except for $0.025 \mu \mathrm{g}$. Hemopressin application at the rate of $0.6 \mu \mathrm{g}$ significantly increased the spike activity after 30 minutes. In addition, discharges similar to status epilepticus were observed during seizures. Our findings are in accordance with the reports in literature where $\mathrm{CB}_{1}$ receptor antagonists had proconvulsant effects through $\mathrm{CB}_{1}$ receptors in experimental epilepsy models. Thus, it could be stated that hemopressin acts as a $\mathrm{CB}_{1}$ receptor antagonist. In addition, it was also suggested that hemopressin could be a negative allosteric modulator $(26,39$, 40). However, considering the fact that hemopressin alone could increase seizure, it could be stated that it is a $\mathrm{CB}_{1}$ receptor antagonist rather than a negative allosteric modulator of $\mathrm{CB}_{1}$ receptors.

\section{Conclusions}

Based on the results from the present study, it could be stated that hemopressin could be an endogenous $\mathrm{CB}_{1}$ receptor antagonist. However, this conclusion needs to be verified through immunohistochemical, PCR and western blot studies along with electrophysiological findings. The presence of antagonization for the endogenous cannabinoid system in brain could correct mood disorders involving endocannabinoid system.

\section{References}

1. Bambal G, Çakıl D, Ekici F. Epilepsi Oluşum Mekanizmaları. Konuralp Tip Dergisi 2011; 3: 42-45.

2. Lerner JT, Sankar R, Mazarati AM. Galanin and epilepsy. Exp Suppl 2010; 102: 183-194 .

3. Kovac S, Walker MC. Neuropeptides in epilepsy. Neuropeptides 2013; 47(6): 467-475.

4. Dossi E, Blauwblomme T, Moulard J et al. Pannexin-1 channels contribute to seizure generation in human epileptic brain tissue and in a mouse model of epilepsy. Sci Transl Med 2018; 0: eaar3796.

5. Pacher P, Batkai S, Kunos G. The endocannabinoid system as an emerging target of pharmacotherapy. Pharmacol Rev 2006; 58: 389-462.

6. Katona I, Freund TF. Endocannabinoid signaling as a synaptic circuit breaker in neurological disease. Nat Med 2008; 14: 923-930.

7. Agar E. The role of cannabinoids and leptin in neurological diseases. Acta Neurol Scand 2015; 132: 371-380.

8. Herkenham M, Lynn AB, Little MD et al. Cannabinoid receptor localization in brain. Proc Natl Acad Sci USA 1990; 87: 1932-1936.

9. Wilson RI, Nicoll RA. Endogenous cannabinoids mediate retrograde signalling at hippocampal synapses. Nature 2001; 410: 588-592.

10. Ohno-Shosaku T, Tsubokawa H, Mizushima I et al. Presynaptic cannabinoid sensitivity is a major determinant of depolarization-induced retrograde suppression at hippocampal synapses. J Neurosci 2002; 22: 3864-3872.

11. Kawamura Y, Fukaya M, Maejima T et al. The CB1 cannabinoid receptor is the major cannabinoid receptor at excitatory presynaptic sites in the hippocampus and cerebellum. J Neurosci 2006; 26 : 2991-3001.

12. Romigi A, Bari M, Placidi F et al. Cerebrospinal fluid levels of the endocannabinoid anandamide are reduced in patients with untreated newly diagnosed temporal lobe epilepsy. Epilepsia 2010; 51: 768-772.

13. Citraro R, Russo E, Scicchitano F et al. Antiepileptic action of N-palmitoylethanolamine through CB1 and PPAR- $\alpha$ receptor activation in a genetic model of absence epilepsy. Neuropharmacol 2013; 69: $115-126$.

14. Stella N, Schweitzer P, Piomelli D. A second endogenous cannabinoid that modulates long-term potentiation. Nature 1997; 388: 773-778.

15. Raza M, Pal S, Rafiq A, DeLorenzo RJ. Long-term alteration of calcium homeostatic mechanisms in the pilocarpine model of temporallob epilepsy. Brain Res 2001; 903: 1-12.

16. Wallace MJ, Wiley JL, Martin BR, DeLorenzo RJ. Assessment of the role of CB1 receptors in cannabinoid anticonvulsant effects. Eur J Pharmacol 2001; 428: 51-57.

17. Wallace MJ, Martin BR, DeLorenzo RJ. Evidence for a physiological role of endocannabinoids in the modulation of seizure threshold and severity. Eur J Pharmacol 2002; 452: 295-2301.

18. Kozan R, Ayyildiz M, Agar E. The effects of intracerebroventricular AM-251, a CB1-receptor antagonist, and ACEA, a CB1-receptor agonist, on penicillin-induced epileptiform activity in rats. Epilepsia 2009; 50: $1760-1767$.

19. Arslan G, Alici, SK, Ayyildiz, M, Agar, E. The role of CB1-receptors in the proconvulsant effect of leptin on penicillin-induced epileptiform activity in rats. CNS Neurosci Ther 2013; 19: 222-228. 


\section{$37-42$}

20. Ludanyi A, Eross L, Czirj KS et al. Downregulation of the CB1 cannabinoid receptor and related molecular elements of the endocannabinoid system in epileptic human hippocampus. J Neurosci 2008; 28: 2976-2990.

21. Heimann AS, Gomes I, Dale CS et al. Hemopressin is an inverse agonist of CB1 cannabinoid receptors. Proc Natl Acad Sci USA 2007; 104: 20588-20593.

22. Rioli V, Gozzo FC, Heimann AS et al. Novel natural peptide substrates for endopeptidase 24.15 , neurolysin, and angiotensin-converting enzyme. J Biol Chem 2003; 278: 8547-8555.

23. Scrima M, Di Marino S, GrimaldiM et al. Binding of the hemopressin peptide to the cannabinoid $\mathrm{CB} 1$ receptor: structural insights. Biochemistry 2010; 49: 10449-10457.

24. Dodd GT, Mancini G, Lutz B, Luckman SM. The peptide hemopressin acts through CB1 cannabinoid receptors to reduce food intake in rats and mice. J Neurosci 2010; 30 (21): 7369-7376.

25. Ma L, Jia J, Niu W et al. Mitochondrial CB1 receptor is involved in ACEA-induced protective effects on neurons and mitochondrial functions. Scie Rep 2015; 5: 1-13.

26. Dale CS, Pagano Rde L, Rioli V. Hemopressin: a novel bioactive peptide derived from the alpha1-chain of hemoglobin. Mem Inst Oswaldo Cruz 2005a; 100: 105-106.

27. Hama A, Sagen J. Centrally mediated antinociceptive effects of cannabinoid receptor ligands in rat models of nociception. Pharmacol Biochem Behav 2011; 100: 340-346.

28. Li XH, Lin ML, Wang ZL et al. Central administrations of hemopressin and related peptides inhibit gastrointestinal motility in mice. Neurogastroenterol Motil 2016; 28: 891-899.

29. Pan JX, Wang ZL, Li N et al. Analgesic tolerance and cross-tolerance to the cannabinoid receptors ligands hemopressin, VD-hemopressin $(\alpha)$ and WIN55, 212-2 at the supraspinal level in mice. Neurosci Lett 2014; 578: $187-191$.
30. Paxinos G, Watson C. The Rat Brain in Stereotaxic Coordinates. Sydney: Academic Press, 1986

31. Ayyildiz M, Kozan R, Agar E, Kaplan S. Sexual dimorphism in the medial vestibular nucleus of adult rats: stereological study. Anat Sci Int 2008; 83: 131-139.

32. Esen M, Aygun, H. The effect of duloxetine on penicillin-induced epileptiform activity in rats. Neurol Res 2018; 41: 298-305.

33. Aygun H, Ayyildiz M, Agar E. Swimming exercise decreases the absence-like epileptic activity in WAG/Rij rats. Behav Brain Res 2019; 363: $145-148$.

34. Fogaça MV, Sonego AB, Rioli V et al. Anxiogenic-like effects induced by hemopressin in rats. Pharmaco Biochem and Behav 2015; 129: 7-13.

35. Cakil D, Yildirim M, Ayyildiz M, Agar E. The effect of co-administration of the NMDA blocker with agonist and antagonist of CB1-receptor on penicillin-induced epileptiform activity in rats. Epilepsy Res 2011; 93: $128-137$.

36. Azad SC, Eder M, Marsicano G et al. Activation of the cannabinoid receptor type 1 decreases glutamatergic and GABAergic synaptic transmission in the lateral amygdala of the mouse. Learn Mem 2003; 10: 116-128.

37. Monory K, Massa F, Egertova $M$ et al. The endocannabinoid system controls key epileptogeniccircuits in the hippocampus. Neuron 2006; 51: 455-466.

38. Wallace MJ, Blair RE, Falenski KW et al. The endogenous cannabinoid system regulates seizure frequency and duration in a model of temporal lobe epilepsy. J Pharmacol Exp Ther 2003; 307: 129-137.

39. Dale CS, Pagano Rde L, Rioli V et al. Antinociceptive action of hemopressin in experimental hyperalgesia. Peptides 2005b; 26: 431-436.

40. Gomes I, Grushko JS, Golebiewska U et al. Novel endogenous peptide agonists of cannabinoid receptors. FASEB J 2009; 23: 3020-3029.

Received July 1, 2019. Accepted August 22, 2019. 